\title{
Improving Student Capstone Experience by Early Exposure and Engagement
}

\section{Dr. David E. Schmidt, University of Pittsburgh}

Dr. David Schmidt is an assistant professor at the University of Pittsburgh Swanson School of Engineering in the department of Mechanical Engineering and Materials Science. His research interests are focused in the areas of computational simulation, additive manufacturing techniques and soft tissue biomechanics. He has broad industrial experience in materials processing, mechanical design and constitutive material model development. Dr. Schmidt is active is in the advancement of undergraduate education through the development of innovative active learning methods.

\section{Dr. Renee M. Clark, University of Pittsburgh}

Renee M. Clark serves as research assistant professor focusing on assessment and evaluation within the University of Pittsburgh's Swanson School of Engineering and its Engineering Education Research Center (EERC), where her interests focus on active and experiential learning. She has 25 years of experience as an engineer and analyst, having worked most recently for Walgreens and General Motors/Delphi Automotive in the areas of data analysis, IT, and manufacturing. She received her $\mathrm{PhD}$ in Industrial Engineering from the University of Pittsburgh and her MS in Mechanical Engineering from Case Western while working for Delphi. She completed her postdoctoral studies in engineering education at the University of Pittsburgh. 


\title{
Improving Student Capstone Experience by Early Exposure and Engagement
}

\author{
David E. Schmidt and Renee M. Clark
}

\begin{abstract}
Many mechanical engineering students entering the capstone course struggle with the open-ended nature of the experience. While students are eager to apply their technical skills in a design environment, proficiency with professional skills can represent the greatest barrier to success. While freshman and sophomores are exposed to these skills, they must be applied and reflected upon in a contextualized environment relevant to mechanical engineering to fully mature. This paper describes a new undergraduate capstone program that includes a one-credit course that exposes underclassman to relevant capstone professional skills and cultivates engagement and enthusiasm among students early in the curriculum.
\end{abstract}

This one-credit elective course was developed to complement a single semester capstone course and is recommended for sophomores and juniors who will be working on their capstone projects in the next one to two years. Titled "Fundamentals of Engineering Projects," the course addresses a broad range of subjects relevant to the mechanical engineering capstone experience including the development of design specifications, application of professional codes and standards, oral and written presentation techniques, prototyping, and project management. The intent of the course is to generate awareness early in the undergraduate program and establish a base of reference materials for use in the senior year. Having developed the course with an active and experiential learning structure, each class meeting has three components - a brief lecture, an active learning exercise, and mini-presentations, including by current capstone students. The interactions in this course are part of our framework to engage and network underclassman with capstone seniors, as their real-time example provides an invaluable demonstration tool to the underclassmen. Underclassmen in the one-credit course are likewise invited to participate in key capstone exercises, including a mid-semester, peer-based design review as well as a final symposium. This student engagement and undergraduate networking has far reaching benefits, as the students involved enrich their own experiences and become resources to pass information and critiques along to one another.

Our plan for assessing this program and its students involves following the participating students throughout the sophomore, junior and senior years. Students, at varied stages in the curriculum, along with their mentors and industry sponsors, will be interviewed to assess the effectiveness of the introductory course and the influence of early exposure to the capstone experience on their capstone projects. Project performance will also be compared pre to post-program to assess program effectiveness. The preliminary experience of the instructor suggests that sophomores and juniors value the engagement with seniors.

\section{Introduction}

Students often struggle with the open-ended nature of their capstone project experience. This experience is so valuable because it provides a contextual basis to synthesize traditional coursework with professional skills. While many influences impact their success, assessment of our past capstone cohorts has identified two dominant factors associated with poor performing senior teams: an incomplete understanding of the capstone process at the course onset and a lack of proficiency with professional skills. Well-formed planning, communication and team skills 
are often differentiating characteristics for successful project teams (Howe et al., 2009). As undergraduate engineering students must be instructed in solving "real world" practical problems (i.e., open-ended or ill-structured), we propose an educational framework within a multi-year capstone program to provide instruction on the professional skills necessary to prepare them for and support their open-ended capstone experience and transition towards career (Jonassen et al., 2006; Incropera \& Fox, 1996; Harris \& Jacobs, 1995). This paper provides a blueprint for our new capstone program. As this program and its evaluation are in the beginning stages, we discuss our plan for the program, including the assessment and evaluation plan, with assessment results to be presented in future publications.

Our senior design projects require the scaffolding of project teams by the instructor, other faculty members, and industry professionals. Scaffolding entails the supports provided to students, often taking the form of apprenticeship-type guidance or just-in-time help during problem solving (Collins et al., 1989). As discussed in the problem-based learning (PBL) literature, scaffolding is required when learning to solve complex problems (Jonassen, 2011). Scaffolding of students during problem-based activities was previously described for biomedical engineering students, in which cognitive and metacognitive skills for problem solving were taught through expert guidance, or cognitive apprenticeships (Newstetter, 2005; Collins et al., 1989). Through our new capstone program, we are establishing a system of instruction and student peer networking that provides scaffolding in the context of team-based professional skills for complex, open-ended problem solving. This system is intended to support current capstone students as well as underclassmen who will work on their capstone projects in the next one to two years.

While capstone students are eager to apply their technical skills in a design environment, proficiency with professional skills can represent the greatest barrier to success. Although these skills are touched upon throughout the curriculum and highlighted again in the capstone course, the abstract nature of these abilities requires repetition within a contextual basis to effectively develop within a higher cognitive domain.

In support of our students' development of the strategy knowledge needed for open-ended problem solving in a team environment, we recently introduced a new one-credit elective course (MEMS-1038) to our mechanical engineering and materials science curriculum entitled "Fundamentals of Engineering Projects" that provides a foundation for our new capstone program. This elective course, open to sophomore and junior students, is focused on exposing students to professional and practical skills relevant to their senior capstone projects. This new course provides an opportunity for students to explore and evolve their professional skills through a series of team-based activities tied to the capstone objectives. Students explore professional and technical skills including needs definition, brainstorming, niche technology awareness, project management, and oral presentation techniques. The intent of the course is to provide exposure early in the undergraduate program and establish a base of reference materials for use in the senior year. In addition, we have embedded events that encourage underclassman to interact with seniors active in their capstone experience. Other engineering schools have also identified the need to better prepare students via the curriculum for their senior design projects (Elsaiah \& Jansson, 2016). Specifically, Bucknell University introduced such a course to prepare their juniors through experiences in teamwork, hands-on activities such as 3-D printing, general design processes, technical presentations, and overall professionalism. 


\section{Methods}

With the intent to enhance our students' capstone experience, we have developed a program to synthesize traditional coursework with professional skills. The framework presented supports a mechanical engineering and materials science department with a total enrollment of 680 students (2016-2017) and mimics the environment of a professional workplace. Our capstone is a single semester course offered three times a year to a senior community of approximately 180 students. The course contains a hybrid of mechanical engineering $(90 \%)$ and materials science students $(10 \%)$. In a typical term, approximately 20 teams of four are formed in the capstone course.

\section{Capstone Program Design}

Our design objective was to create a dynamic capstone program that fosters continuous student preparation and engagement beginning in the sophomore year. With the program, students are presented with a spectrum of opportunities to interact with peers ranging from sophomores to seniors. Our intent was to instill a proactive and enthusiastic attitude towards the capstone experience and to develop strong collaborative ties between students at varied stages in the curriculum. As illustrated in Figure 1, this framework depicts the capstone as an evolving program rather than a single course in the senior year. Among the students and faculty, this approach is aimed at creating a common mindset of growth building to the capstone experience.

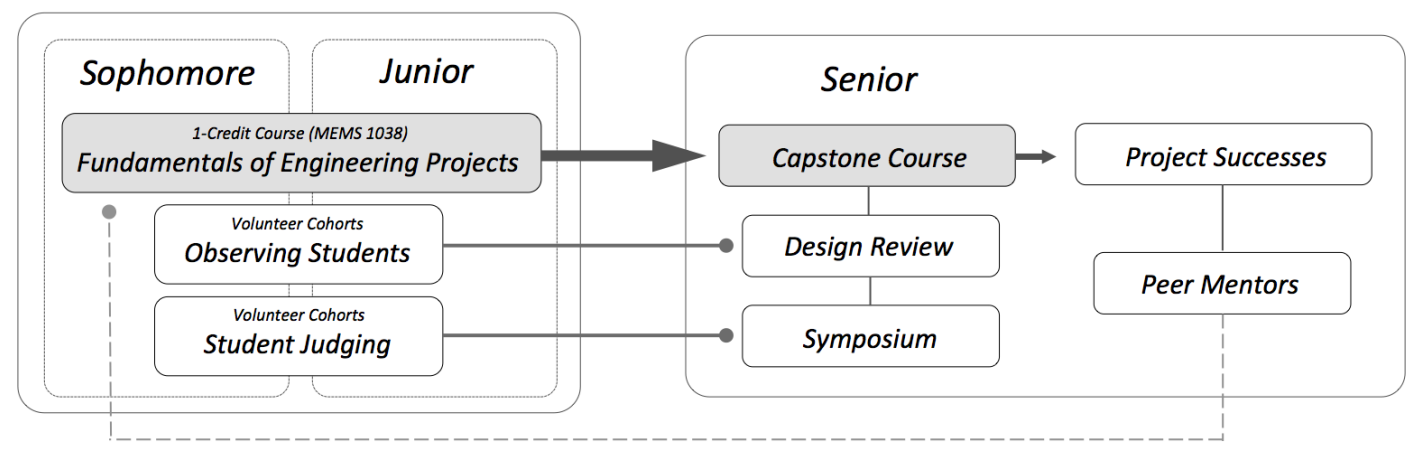

Figure 1. Network for Student Engagement in a Capstone Program

Both the one-credit and the capstone courses are taught by the same mechanical engineering instructor, who provides key hands-on leadership in establishing the network of undergraduates who are engaged with the program. Active networking is intended to occur among students at varied stages in the curriculum. Given the structure of the courses, there is typically little interaction among sophomores, juniors and seniors. In our program we encourage peer engagement and interaction through post-capstone mentors and voluntary underclassmen participation in capstone events. Sophomores and juniors are encouraged to interact with the capstone course at two events - a midterm public design review and a final symposium. Sophomore and junior students can register to attend these events and actively participate in the project critiques. Periodically, seniors from the capstone course are invited to give a brief presentation related to their current project challenges to the one-credit Fundamentals class. Students often comment that "hearing seniors talk about their capstone experience" is invaluable in their preparation for the senior year and offers insights only attainable from student peers. In essence, it provides them early-on with a view of the "other side." Discussion of the positive 
impact of these interactions among the student body has become one of the key motivators for underclassmen to enroll in the elective course.

\section{Fundamentals of Engineering Projects Course Design}

The new one-credit course in engineering project fundamentals has the following learning objectives:

- Develop professional skills relevant to the capstone project experience and beyond.

- Recognize common pitfalls in project preparation and execution.

- Develop skills to overcome unanticipated problems in an open-ended project setting.

- Practice effective team dynamics skills.

- Develop strong presentation skills and practice the organization of technical data.

The class structure mimics the working environment encountered by project teams in the capstone course. Each class meeting involves an open-ended collaborative activity that requires students to complement the strengths of their peers. Following a brief lecture by the instructor, teams formulate a response to a prompt embedded with a moderate degree of ambiguity. At the conclusion of each exercise, project teams must present their work to the class - a process that reinforces the importance of communication, feedback, and reflection.

The following example illustrates an in-class exercise that followed a lecture on the development of a system requirements document. Six project teams were given product variations of a popular commercial bike rack system. All of the products shared the same common goal of supporting two bicycles, but each used a different attachment scheme (e.g., roof mount, truck mount, or toe hitch mount). Using reverse thinking, the teams were prompted to develop a set of product requirements to describe elements of the as-designed configuration. Upon completion, the teams interfaced with each other to classify their requirements as either common to all systems or unique to their specific mounting arrangements. Each group presented its results in a short presentation. While the primary objective of this exercise focused on defining appropriate requirements and specifications, the format offered the opportunity for the instructor to highlight the influence of "professional skills" on the process. Illustration of the impact of brainstorming techniques, organization, and communication is a natural byproduct of the exercise. Students take away a tangible example that can be used to scaffold their capstone project experience.

In addition to offering a deeper treatment of topics discussed within the capstone course, such as needs definition, project management, and effective presentation of technical information, the one-credit course also covers niche technical skills typically needed during the capstone such as prototyping, 3D printing, and design for manufacturing. Students are introduced to these topics in a contextual setting that is reinforced with a team exercise. The intent is to provide exposure and generate awareness rather than to provide a comprehensive treatment. Students are provided with detailed reference materials for further study and for their capstone project experience.

Our new course is also non-traditional in the sense that course assessment is based on participating during class on team-based activities, with no exams or tests. Some direct instruction is provided, but the focus is on "doing" and "experiencing" related to open-ended 
projects. As discussed in a recent article, preparing students to face challenges is not necessarily aided by today's focus on "teaching to the test" and the aim to excel on exams (Taylor, 2016). Rather, teachers should be "watchful" Socratic mentors, supporting and guiding students in learning to think independently, in particular through project work. The course is entirely teambased; teams formed in the first week are maintained throughout the semester.

\section{Student Recruitment}

Our primary recruitment path for the elective course is actually through the core courses in the curriculum. Each semester in core sophomore and junior courses, a brief announcement and presentation on the format and benefits of the elective course is made by the Project Fundamentals instructor, who is also the capstone instructor. Typically, he highlights several of the capstone projects from the previous term and discusses the path towards the capstone course. Additionally, he recruits through the student ASME organization.

\section{Post-Capstone Peer Mentors}

Often seniors remain in the undergraduate program for one more term after completing the capstone course. We have recognized that these students are a valuable resource to the capstone program. Students associated with exemplary projects are invited to serve as undergraduate teaching assistants for the capstone course. We refer to them as "post-capstone" peer mentors and encourage them to engage with capstone students at all stages of their projects. In addition, the mentors are involved in the development of new instructional materials. We have found their post-capstone insight to provide a unique lens through which to understand the student experience. Recently, a peer mentor suggested that we develop tools to help teams to process intra-team criticism, such as critique of a team member's proposed approach by fellow team members. The mentor had experienced this form of team dynamics in his own capstone project and was impactful in developing a set of communication techniques that can be employed during team meetings. In general, the mentors serve to support students at different stages of the curriculum.

\section{Underclassmen Volunteer Cohorts}

On a volunteer basis, sophomore and junior students from various sources, including the onecredit course, the student ASME chapter, or students recruited by the ASME chapter, are invited to participate in two key milestone events in the capstone course. Near the midpoint of the term, seniors in the capstone participate in a team-based peer design review. In pairs, teams present their preliminary design concepts and are in turn reviewed by a fellow team. This review helps to guide the process of finalizing an adopted design approach. Underclassmen are invited to attend the event to observe the process. They are encouraged to participate in the reviews and add to the discussion where appropriate. Observation of their participation illustrates that the underclassmen enhance the technical discussion, as many of these students have valuable experience developed through co-op rotations and internships. An assignment in the capstone course requires the senior teams to formally address the critiques of the underclassmen. The review has been well attended by the underclassmen - typically they represent $30 \%$ of the students present. 
Our capstone course ends with a public symposium and school-wide Design Expo where each capstone team delivers a podium presentation and participates in a poster session. A cohort of underclassmen volunteers organized through the student ASME chapter is tasked with assessing the posters and providing a recommendation for consideration by the judging faculty. This directly engages all of the students and provides an awareness of each capstone project to the underclassmen. Sophomores and juniors are also encouraged to attend the podium presentations to observe the "professional" presentation skills developed by the seniors.

\section{Assessment Plan}

Our plan for assessing this newly-developed capstone program includes interviewing students throughout their undergraduate careers to investigate their preparation for and experiences related to their capstone project and beyond. Specifically, the program assessment analyst will interview students taking the MEMS-1038 one-credit course and the capstone course as well as students in between (that the instructor is able to recruit and engage in the program). We will also analyze students' performance on their capstone projects and the various tasks and activities that contribute to it, including in MEMS-1038. Meaningful comparisons will be done, including comparisons of current capstone projects to projects from prior years. A list of potential student interview or focus group questions in Table 1 details our assessment and evaluation questions of interest. The questions relate to preparation, experiences, and behaviors of interest to us.

Table 1: Student Interview/Focus Group Questions

\begin{tabular}{|c|c|}
\hline & MEMS-1038 Students (Fundamentals of Engineering Projects) \\
\hline 1) & What will you use or apply from MEMS-1038 going forward? \\
\hline 2) & Has MEMS-1038 inspired you to possibly come up with your own senior design project in the future? \\
\hline 3) & Has MEMS-1038 created any excitement for you for your future senior design project? \\
\hline 4) & How did the interaction in MEMS-1038 with senior design students impact you? \\
\hline 5) & $\begin{array}{l}\text { Do you anticipate that you'll view yourself as a future leader within your senior design team having taken } \\
\text { MEMS-1038? }\end{array}$ \\
\hline 6) & Has MEMS-1038 impacted your confidence for your future senior design project? \\
\hline \multirow[t]{2}{*}{ 7) } & $\begin{array}{l}\text { Which assessment format would be better for your learning and/or engagement in MEMS-1038: a) } \\
\text { combination of attendance and in-class team exercises (the method used), or b) exams and tests? }\end{array}$ \\
\hline & Senior Design/Capstone Students \\
\hline 8) & What knowledge or skills have you used or applied from MEMS-1038 in your senior design project? \\
\hline 9) & What impact did MEMS-1038 have on your senior design project? \\
\hline 10) & Did you benefit from presenting aspects of your senior design project to students in MEMS-1038? \\
\hline \multirow[t]{2}{*}{ 11) } & $\begin{array}{l}\text { Would you have benefitted from additional preparatory training (such as offered in MEMS-1038) for your } \\
\text { senior design project? }\end{array}$ \\
\hline & Students at Various Levels \\
\hline 12) & Comment on the mid-term design reviews that you may have attended. \\
\hline 13) & $\begin{array}{l}\text { What in-class activities or assignments from MEMS-1038 (Fundamentals of Engineering Projects) had the } \\
\text { most positive impact on you? }\end{array}$ \\
\hline 14) & Did or will MEMS-1038 change the way you approach problems? \\
\hline 15) & Did MEMS-1038 impact any other courses you've taken or engineering jobs you've had? \\
\hline 16) & Would you recommend MEMS-1038 to underclassmen? \\
\hline 17) & Would you recommend any additions to the MEMS-1038 curriculum or syllabus? \\
\hline 18) & What are the advantages to presenting your work in front of your classmates or peers? \\
\hline
\end{tabular}

We also plan to interview the various mentors involved in working with the students to determine their impressions of the students' preparation, professional behaviors, and 
performance, providing a means for triangulation with the students' responses. These mentors include the capstone instructor and other faculty and industry professionals who serve as project sponsors. The list of questions in Table 2 describes our student and program evaluation questions of interest. The questions again relate to student preparation, experiences, and performance, in particular compared to prior years.

\section{Table 2: Mentor Interview/Focus Group Questions}

1) Have you noticed particular skills or competencies that are notable with the current senior design teams or improved compared to prior teams?

2) What are your observations of team effectiveness with the current senior design projects or compared to prior projects?

3) What are your impressions of the overall quality of the current senior design projects, including in comparison to prior projects?

4) Have you noticed any areas in which senior design teams struggle or are not prepared for successfully completing the projects?

5) What impact do you believe MEMS-1038 (Fundamentals of Engineering Projects) has had (or has the potential to have) on students, including for their senior design projects?

6) Comment on the instructor's overall approach to "teaching" senior design and open-ended projects (e.g., mid-term design reviews/presentations by seniors involving underclassmen, involving underclassmen, including an Introduction to Engineering Projects course, etc.)

7) Would you recommend any additions or changes to the curriculum or students' preparation to enhance senior design project performance?

\section{Summary and Discussion}

We have observed that exposing students to the capstone process early in the curriculum instills needed preparation as well as a proactive and enthusiastic attitude towards the capstone experience. In fact, we have experienced an increase in the number of student-originated capstone projects since starting the program, including projects developed by self-forming clubs such as the Human Powered Vehicle club. The foundation of our new capstone program, which is aiming to formalize this proactive approach, is a one-credit Fundamentals of Engineering Projects course, in which sophomores and juniors practice various professional and technical skills (in context) needed for open-ended projects such as the capstone experience. Also critical to our program is the creation and maintenance of active networking among all mechanical/ materials engineering undergraduates, which is led by the instructor of the capstone and onecredit courses. These engaged and participating undergraduates include post-capstone peer mentors as well as sophomores and juniors who voluntarily observe design reviews and provide other types of feedback to the seniors, allowing them to get an "early view" of the skills and behaviors required for the capstone. Our assessment plan will provide us with comprehensive formative and summative assessment of our capstone program by gathering perception data from all involved students and their mentors as well as by analyzing actual project outcomes and deliverables pre to post-program. 


\section{References}

1. Collins, A., Brown, J., \& Newman, S. (1989). Cognitive Apprenticeship: Teaching the Crafts of Reading, Writing, and Mathematics, In L. Resnick (Ed.), Knowing, Learning, and Instruction: Essays in Honor of Robert Glaser, (453-494), Hillsdale, NJ: Lawrence Erlbaum Associates.

2. Elsaiah, S., \& Jansson, P. (2016). An Effective Design Course to Inspire Active Learning in Undergraduate Education. Proceedings of the Annual Frontiers in Education Conference, Erie, PA.

3. Harris, T., \& Jacobs, H. (1995). On Effective Methods to Teach Mechanical Design. Journal of Engineering Education, 84(4), 343-349.

4. Howe, S., Lasser, R., Su, K., \& Pedicini, S. (2009). Content in Capstone Design Courses: Pilot Survey Results from Faculty, Students \& Industry. Proceedings of the ASEE Annual Conference, Austin, TX.

5. Incropera, F., \& Fox, R. (1996). Revising a Mechanical Engineering Curriculum: the Implementation Process. Journal of Engineering Education, 85(3), 233-238.

6. Jonassen, D., Strobel, J., \& Lee, C. (2006). Everyday Problem Solving in Engineering: Lessons for Engineering Educators. Journal of Engineering Education, 95(2), 139-151.

7. Newstetter, W. (2005). Designing Cognitive Apprenticeships for Biomedical Engineering. Journal of Engineering Education, 94(2), 207-213.

8. Taylor, J. (2016). The Examined Life. Aeon Magazine. 